\title{
Effect of capsaicin on voltage-gated currents of trigeminal neurones in cell culture and slice preparations
}

\author{
Zs. Balla, Éva Szőke, G. Czéh, J. Szolcsányi \\ Neuropharmacology Research Group of Hungarian Academy of Sciences at Department of Pharmacology \\ and Pharmacotherapy, Pécs University, Faculty of Medicine, Pécs, Hungary
}

Received: February 5, 2002

Accepted: March 25, 2002

\begin{abstract}
Effects of capsaicin on voltage-gated currents were examined in vitro by whole-cell patchclamp recordings from small neurones of rat trigeminal ganglia either in slice preparations or in different cell cultures.

Cells were classified as sensitive to capsaicin if they responded with inward current and/or conductance change to the agent in nanomolar concentration. Capsaicin (150 to $330 \mathrm{nM})$ in sensitive cells reduced the mixed inward current evoked by depolarizing step or ramp commands in all preparations. In cultured cells, the inward current was depressed to $32.78 \pm$ $26.42 \%(n=27)$ of the control. Both the tetrodotoxin-sensitive and -resistant inward currents were affected. The data support the concept that capsaicin besides acting on VR-1 receptors inhibits also some voltage gated channels. In 34 cultured cells, capsaicin increased the slope conductance to $170.5 \pm 68 \%$. Percentage of capsaicin sensitive cells observed in nerve growth factor-treated cultured cell populations was higher (77.8\%) than in the two other preparations $(14.3$ or $38.8 \%)$.

It is concluded that 1) depression of the voltage-gated currents may play an important role in the functional desensitization of the sensory receptors and in the analgesic effect induced by the agent and 2) cell body of sensory neurones under native condition seems less sensitive to capsaicin then that of cells cultured in the presence of nerve growth factor.
\end{abstract}

Keywords: cationic currents, nerve growth factor (NGF), sensory desensitization, nociceptive neurones, vanilloid (VR1)-receptors, whole-cell patch clamp

Correspondence should be addressed to

János Szolcsányi M.D. DSc.

Department of Pharmacology and Pharmacotherapy

Faculty of Medicine

University of Pécs

H-7643 Pécs, Szigeti u. 12, Hungary

Phone: 36-72-536-218

Fax: 36-72-536-324 
Capsaicin (CAPS), the natural pungent agent of the red pepper, selectively activates the hot responsive capsaicin (vanilloid, VR-1) receptor cation channel complex of a major subset of nociceptive primary afferent neurones $(11,40,41,44,46)$. Behavioral studies, as well as single unit recordings from cutaneous sensory nerves, have provided firm evidence that CAPS, after initial stimulation, desensitizes the polymodal nociceptors to their natural stimuli $(42,44,45)$. Unresponsiveness to CAPS or noxious heat stimuli can be attributed to a loss of function of the VR-1 receptors, but the cellular mechanism of long-lasting sensory desensitization to mechanical and various chemical stimuli is unknown. Besides sensory receptors, somatic membrane of a major subset of small (type B) trigeminal and dorsal root ganglia (TRG and DRG) neurones are also sensitive to direct application of CAPS even if their terminal arborization has been removed $(3,18)$.

Cell body of CAPS-sensitive sensory neurones respond to pungent agents with a concentration-dependent depolarization, often accompanied by action potentials and conductance changes in intracellular recordings $(1,16,21,25)$. In voltage-clamped CAPS-sensitive sensory neurones, CAPS opens cationic channels which appear identical with the VR-1 receptor and elicits inward membrane currents at negative membrane potentials with a variety of slower or faster waveforms, associated with membrane conductance increase and calcium ion entry (7, 20, 21, 28, 47, 49, 52). Desensitization has been demonstrated upon repeated applications of CAPS $(22,40)$. Important role of calcium ions has been recognized in CAPS evoked inward current and inhibition of voltage $(\mathrm{V})$-gated calcium and potassium currents after application of high $(10-100 \mu \mathrm{M})$ concentration of the agent has been described $(5,6,7,14,18,20,43,44)$. CAPS in that high concentration range, however, inhibits V-gated channels also in nonsensory neurones or in neurones of non-mammalian species, where inward currents, action potentials or behavioral responses can not be elicited by the agent $(18,43,44)$. Piper et al. (30) demonstrated that acute desensitization of responses to CAPS depends on membrane potential, perhaps due to dephosphorilation of the ion channel/receptor complex.

In nociceptive sensory neurones of mammals, CAPS initiates action potential with the contribution of $\mathrm{V}$-gated channels. Ionic currents in sensory neurones have been studied in detail $(9,10,15,31-35)$. It is an unexplored possibility how far a coupling between specific capsaicin receptor activation and $\mathrm{V}$-gated responses of the neuronal membrane could participate in desensitization. The present paper reports effects of low concentration of CAPS on V-gated currents in TRG. Cultured or acutely isolated cells were examined as well as other cells in slice preparations under conditions similar to their in vivo chemical micro-environment. The findings reported here suggest that CAPS in nanomolar concentration influence V-gated currents, can block sodium current activation for many minutes after washout, and points to critical role of NGF in shaping the cellular responses to activation of the capsaicin receptors. 


\section{Materials and Methods}

\section{Cell cultures}

Primary cultures of TRG neurones were made from 32 Wistar rat pups of 1-7 days old, incubated for 40 minutes at $37{ }^{\circ} \mathrm{C}$ in a phosphate-buffered solution (PBS) containing collagenase (Type XI) and then in PBS with deoxyribonuclease I for 8 min. The ganglia were then rinsed with $\mathrm{Ca}^{2+}$ and $\mathrm{Mg}^{2+}$ free PBS and dissociated by trituration. TRG cells were plated on poly-D-lysin-coated glass coverslips and grown in a nutrient-supplemented medium. Nerve growth factor (NGF, $200 \mathrm{ng} / \mathrm{ml}$ ) was added into the medium in one series of experiments and omitted in others. The coverslips were maintained at $37{ }^{\circ} \mathrm{C}$ in a water-saturated atmosphere with $5 \% \mathrm{CO}_{2}$. Experiments were performed at room temperature in extracellular solution 1-8 days after TRG cells had been plated.

\section{Acutely isolated cells}

Ganglia of 6 pups were prepared for recordings from acutely isolated cells. The dissected TRGs were incubated at $34{ }^{\circ} \mathrm{C}$ for $50 \mathrm{~min}$ in calcium- and magnesium-free artificial cerebrospinal fluid containing collagenase (Type Ia) and pronase $\mathrm{E}$ and digestion was terminated by a wash for $1 \mathrm{~min}$ in trypsine inhibitor. Cells were dissociated by trituration in HEPES buffered artificial cerebrospinal fluid and plated on glass coverslips which were moved to the chamber in less then 4 hours after plating.

\section{Slice preparations}

Wistar rat pups $(n=52$, age between 3-12 postnatal days) were deeply anesthetized with ether, submerged in icy water and their brain was quickly removed. Care was taken to minimize suffering of pups. Trigeminal ganglia were dissected free under continued perfusion of ice-cold oxygenated artificial cerebrospinal fluid containing high $\mathrm{Mg}^{2+}$ and low $\mathrm{Ca}^{2+}$ concentrations. After removal of the connective tissue, $400 \mu \mathrm{m}$ thick slices were cut with a vibratome (Campden Vibroslice) and the slices were allowed to warm up slowly in oxygenated artificial cerebrospinal fluid. Some slices from the older (7-12 days) pups were exposed to collagenase (Type IV) for 5-10 minutes to facilitate cleaning of cells. 


\section{Electrophysiological procedures}

Cells were visually selected for patch-clamp recording according to the following criteria: small size (below $30 \mu \mathrm{m}$ diameter), sharp contour, homogeneous texture without cytoplasm segregation, and no sign of cytoplasm swelling. Patch clamped cells were accepted for further study if the seal resistance was at least $1 \mathrm{GOhm}$, the access resistance was below $20 \mathrm{MOhm}$, the estimated membrane potential was more negative than $-50 \mathrm{mV}$, the clamp-current remained stable and weak for several minutes at -60 or $-70 \mathrm{mV}$ holding potential, and the neuron responded with robust current to step or ramp voltage command protocols. CAPS application (single or repeated) was made only one cell per slice or plate.

An Olympus BX50WI upright microscope with differential interference contrast optics was used with a $\mathrm{x} 40$ (NA 0.8) water immersion objective to find cells. Images were recorded with a digital (12 bit) cooled camera (CCD, SensiCam PCO, Germany) attached to the microscope and connected to a Pentium II PC (Supertech Gmbh, Hungary) which controlled the electrophysiological system, too. The computer runs simultaneously the Axon Imaging Workbench 2.1 and the pClamp 7.0 software packages (both from Axon Instruments, Foster City CA) for data acquisition. Electrophysiological data and images taken from each cells were stored on the computer disk and on a DRA-400 recorder (Bio-Logic, France) and processed off-line.

TRG cells were voltage-clamped according to the now conventional whole-cell patch clamp method with an Axopatch 200B (Axon Instruments, Foster City, CA) amplifier. A Burleigh PCS 5400 manipulator was used to advance the pipettes. Vibration was eliminated with a modified (Supertech Gmbh, Hungary) table. Experiments were performed at room temperature. Slices were held with pieces of platinum wires in the bottom of a chamber (volume $0.23 \mathrm{ml}$ ) and perfused with oxygenated artificial cerebrospinal fluid (rate $3-5 \mathrm{ml} / \mathrm{min}$ ). Isolated cells were studied in HEPES buffered solution without oxygen supply in a larger (volume $1.2 \mathrm{ml}$ ) chamber. An $\mathrm{Ag}-\mathrm{AgCl}$ pellet in the bath connected to the amplifier grounded the preparation. Electrodes were fabricated from borosilicate (KTW 150 F-3, WPI) glass with a PC 33 puller (Narishige, Japan), fire-polished to $1-3 \mu \mathrm{m}$ opening, and had a final resistance in the range between 2 and $5 \mathrm{MOhm}$.

Capsaicin was added to the bath with one of the following techniques: 1) Fluids were moved from bottles to the chamber via two separate polyethylene tubes by a Minipuls 3 (Gilson, France) peristaltic pump. One tube was used to supply artificial cerebrospinal fluid alternating with the other filled up with CAPS. This technique allowed continuous wash of the preparation with known concentration of CAPS and calculated complete fluid exchange in the small chamber was less than $5 \mathrm{sec}$. Wash in was restricted for $1 \mathrm{~min}$ or less in sensitive cells, but kept on for up 5 minutes when the 
cell failed to respond rapidly. 2) The perfusion of artificial cerebrospinal fluid was stopped for $1 \mathrm{~min}$, and CAPS was added with Finnpipette to the chamber in a way to reach the desired dilution when mixed with the bath. 3) Fast superfusion system through a polyethylene tube with orifice placed at a distance of $150-200 \mu \mathrm{m}$ from the soma of a selected neuron. CAPS was moved by the peristaltic pump as above. Complete exchange of the solutions was irrelevant with this technique because the patch-clamped cells were washed directly with the test solution.

\section{Data processing}

The basic membrane properties (input resistance and capacitance, time constant as well as seal resistance and holding current intensity) of the cell was determined by pClamp version 7.0 (Axon Instruments, Foster City, CA). V-gated channels were tested both with traditional step commands and with a variety of depolarizing ramps.

Several varieties of step command protocols were used. Initial downsteps to $-100 \mathrm{mV}$ for 20 to $500 \mathrm{~ms}$ from the $-60 \mathrm{mV}$ holding potential were used in many cells. Since this hyperpolarizing priming increased step evoked sodium currents to levels difficult to control, the priming was often switched off. Depolarizing commands were given for 20-200 ms in various (range 1-10 mV) increments delivered in $3 \mathrm{sec}$ intervals. Peak intensities of the inward current were measured and the data were normalized to the maximum intensity of current to obtain I-V curves. Either the $\mathrm{p} 4$ protocol was used to leak subtraction, or a $10 \mathrm{mV}$ step of identical length of the step pulses were delivered after each command, the current to this step were averaged and scaled appropriately to calculate leak-subtracted step evoked current data.

Ramp command protocols started with a step to $-100 \mathrm{mV}$ from the holding potential and remained steady at this negative potential for $20 \mathrm{msec}$ before the depolarizing ramp was initiated. Positive endpoint of the ramps was set into the range of -30 and $+100 \mathrm{mV}$. Rate of voltage changes was set within the $0.03 \mathrm{mV} / \mathrm{ms}$ to $3 \mathrm{mV} / \mathrm{ms}$ range. These protocols could be repeated with intervals of 5-8 sec without depressing the evoked currents. Membrane current data were plotted against command voltage to obtain ramp I-V curves. No leak subtraction was used with ramp protocols.

Baseline current seen at the holding potential (called clamp-current in this report to distinguish from step or ramp command-evoked current responses) was recorded either continuously with a DRA-400 recorder (Bio-Logic, France) with a digitizing rate of $44 \mathrm{kHz}$, or sampled only in the selected time windows of the pClamp software. Continuous recordings were redigitized at lower rate, filtered when needed and displayed with the pClamp suite. 
Cell diameter was determined as follows. The picture of the studied cell was cut out of its environment in the recorded image, and pasted to the image of a calibration scale $(10 \mu \mathrm{m}$ divisions $)$ recorded with the $\mathrm{x} 40$ objective and the camera. Rotation of the cells picture over the scale allowed to measure the minimal and maximal diameters, the mean of which was given to characterize cell sizes.

Calculated averages are given with their standard deviation throughout in this paper.

\section{Solutions and materials}

For the experiments with TRGs slice and acutely isolated cells, solution used for preparation of the ganglia contained high $(5 \mathrm{mM}) \mathrm{Mg}^{2+}$ and low $(0.5 \mathrm{mM}) \mathrm{Ca}^{2+}$ in addition to the other components $(\mathrm{mM}): \mathrm{NaCl}, 125 ; \mathrm{KCl}, 2.5 ;$ glucose, 25; $\mathrm{NaH}_{2} \mathrm{PO}_{4}$, 1.25; $\mathrm{NaHCO}_{3}, 24$ at $\mathrm{pH} 7.4$ when oxygenated with $95 \%-5 \%$ mixture of $\mathrm{O}_{2}-\mathrm{CO}_{2}$. The solution used for incubating the slices before measurements as well as for perfusion of the chamber contained $2 \mathrm{mM} \mathrm{CaCl}_{2}$, and $1 \mathrm{mM} \mathrm{MgCl}$, in addition to the components listed above. For the experiments with acutely isolated cells bicarbonate-phosphate buffer was replaced with $10 \mathrm{mM}$ HEPES both in plating and recording sessions. On the cell cultures the extracellular solution contained the following $(\mathrm{mM}): \mathrm{NaCl}, 110$; cholin-chloride, 50; $\mathrm{KCl}, 2.5 ; \mathrm{CaCl}_{2}, 1 ; \mathrm{MgCl}_{2}, 2$; HEPES, 10; glucose, 10; $\mathrm{pH}$ 7.3.

Connective tissue was softened by collagenase Type IV (2\%) applied to the slices. Collagenase Type Ia $(0.03 \mathrm{mg} / \mathrm{ml})$, pronase $\mathrm{E}(0.12 \mathrm{mg} / \mathrm{ml})$ and trypsine inhibitor ( $1 \mathrm{mg} / \mathrm{ml}$ artificial cerebrospinal fluid) was used for acute isolation. For cell culture, collagenase Type XI ( $2 \mathrm{mg} / \mathrm{ml})$ and DNase $(0.5 \mathrm{mg} / \mathrm{ml})$ were used.

The nutrient-supplemented cell culture medium composed of $180 \mathrm{ml}$ Dulbecco'sModified Eagle Medium, $20 \mathrm{ml}$ horse serum, $20 \mathrm{ml}$ bovine albumin, $2 \mathrm{ml}$ insulintransferrin-selenium-S, $3.2 \mathrm{ml}$ putrescin dihydrochloride $(100 \mu \mathrm{g} / \mathrm{ml}), 20 \mu \mathrm{l}$ triiodothyronine $(0.2 \mathrm{mg} / \mathrm{ml}), 1.24 \mathrm{ml}$ progesterone $(0.5 \mathrm{mg} / \mathrm{ml}), 100 \mu \mathrm{l}$ penicillin, $100 \mu \mathrm{l}$ streptomicin.

Three kinds of patch pipette solutions were used. One contained (mM): $\mathrm{KCl}, 140$; $\mathrm{CaCl}_{2}$, 1; EGTA, 10; HEPES, 10; Mg-ATP, 6; pH 7.3, the second (mM): CsCl, 135; HEPES, 20; $\mathrm{MgCl}_{2}, 2$; Mg-ATP, 6; $\mathrm{pH} \mathrm{7.3,} \mathrm{the} \mathrm{third} \mathrm{(mM):} \mathrm{CsCl,} \mathrm{140;} \mathrm{EGTA,} \mathrm{5;}$ HEPES, 10; $\mathrm{MgCl}_{2}, 1 ; \mathrm{CaCl}_{2}, 0.5 ; \mathrm{Mg}$-ATP, 2; GTP 0.3; pH 7.3.

CAPS was dissolved in saline $(0.9 \% \mathrm{NaCl})$ with the aid of ethanol and TWEEN $80(8: 1: 1)$ to obtain $1 \%$ stock solution. Further dilution was made with artificial cerebrospinal fluid or extracellular solution to reach final concentrations of $150 \mathrm{nM}$, $330 \mathrm{nM}, 1 \mu \mathrm{M}$ or $3.3 \mu \mathrm{M}$ in the bath.

Chemicals were obtained from Sigma, culture media from GIBCO. 


\section{Results}

Pipettes were advanced under visual control to selected cells. Whole-cell tightseal recordings were made from healthy-looking small neurones with a diameter less than $30 \mu \mathrm{m}$ (means of major diameters 25.1, that of minor diameters 21.7, considered mean diameter $23.41 \pm 5.2 \mu \mathrm{m}, \mathrm{n}=83$ ). Main electrophysiological criteria of the selection for testing the effect of CAPS were weak clamp current (often less than $100 \mathrm{pA}$ ) at $-60 \mathrm{mV}$ or $-70 \mathrm{mV}$ membrane potential and activation of robust V-gated currents with depolarizing commands. Altogether 83 cultured neurones were exposed to CAPS within a concentration range of $150 \mathrm{nM}$ to $3.3 \mu \mathrm{M}$ under slightly different conditions. The exposure was restricted for $1 \mathrm{~min}$ or less in sensitive cells.

In a separate control group of neurones CAPS sensitivity was verified first and then the neurones $(n=7)$ were tested with solvents without CAPS. Neither of the effects reported below were detected in them.

\section{A) Effects of CAPS on membrane currents in NGF-treated cultured cells}

Altogether 55 cells were accepted for a study of neurones cultured in media containing also $200 \mathrm{ng} / \mathrm{ml} \mathrm{NGF}$, and 36 of them were tested for CAPS sensitivity. Cells were classified as sensitive (28 of 36 ) to CAPS if they responded with inward clampcurrent beyond $100 \mathrm{pA}$ to the agent in 150 or $330 \mathrm{nM}$ or $1 \mu \mathrm{M}$ concentration $(n=22)$ or their conductance changed together with ambiguous clamp-current responses $(n=6)$. Altogether 73 cells ( 8 from the NGF treated sample and the rest from the other two kinds of preparations) were considered insensitive because up to $3.3 \mu \mathrm{M}$ concentration of CAPS failed to change their clamp-current or membrane conductance.

Responses to step commands in the presence of CAPS

Cells dialised by cesium ions to eliminate potassium currents responded with presumably mixed inward current to depolarizing steps. A rapid and large component of that current could be depressed or even eliminated by $1 \mu \mathrm{M}$ TTX. Around $80 \%$ of the TTX tested cells $(n=22)$ responded with smaller and slower, possibly TTX-resistant (TTX-r) sodium current to the step commands. No effort was made to separate subtypes of TTX-r components (31) and to distinguish between sodium and calcium-mediated inward currents.

Step-evoked current data were used to generate activation curves (Fig. 1F). 
A

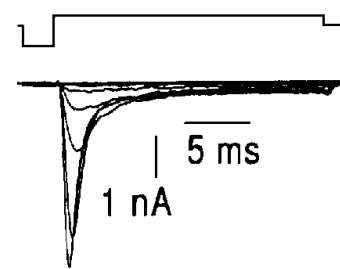

B

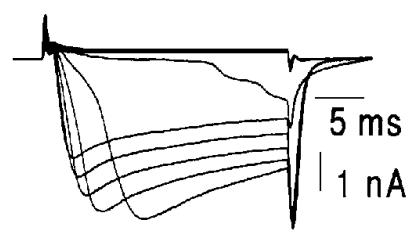

E
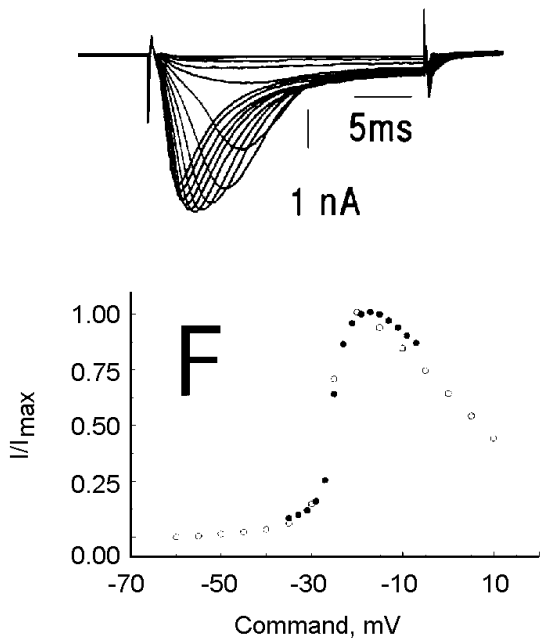

Fig. 1. Mixed current responses of small sensory neurones to depolarizing commands. All data were obtained with $\mathrm{CsCl}$ filled pipettes, and all cells were held at $-60 \mathrm{mV}$. A: The most often seen type with fast peak followed by a prolonged component. Leak subtracted (p4 protocol) recordings, command increments $5 \mathrm{mV}$ in the -60 to $-10 \mathrm{mV}$ range. Top trace is a sample of the command. B: Example of responses with very large slow component. No leak subtraction was used. Commands: $5 \mathrm{mV}$ increments from -45 to $0 \mathrm{mV}$. C: Another often seen type with slower initial peak. D: Same as in C, responses to commands with $2 \mathrm{mV}$ increments from -40 to $-24 \mathrm{mV}$. Leak subtraction with computation. E: Data from another cell obtained in the presence of $1 \mu \mathrm{M}$ TTX. Commands: $\quad 2 \mathrm{mV}$ increments from $-35 \mathrm{mV}$ to $-7 \mathrm{mV}$, leak subtraction with computation. F: Normalized peak current intensity calculated from the data in $\mathrm{E}$ (dots) and from another set of curves (circles) obtained in the same cell with $5 \mathrm{mV}$ steps varied between -60 and $10 \mathrm{mV}$ 
A
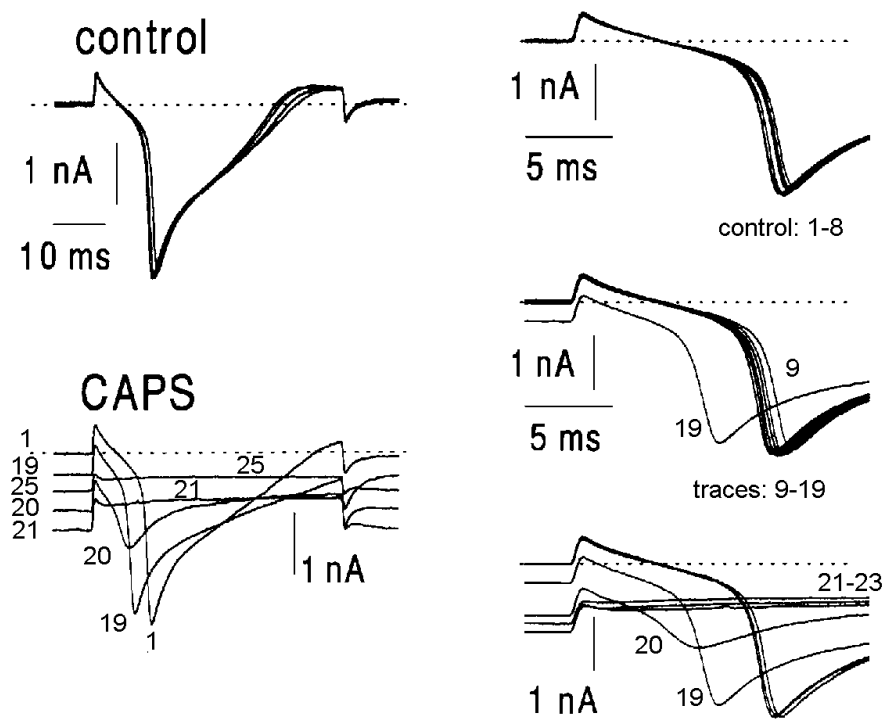

$11,15,18$

Fig. 2. Depression of Vgated inward current by CAPS. A-C: data from a single cell exposed to $1 \mu \mathrm{M}$ CAPS, and tested with constant depolarizing steps to $-10 \mathrm{mV}$ from $-60 \mathrm{mV}$ holding potential, dashed lines at the same current intensity level throughout, and the numbers identify corresponding traces. A, control: superimposed selected traces from a minute-long period. A, CAPS: Major changes in the presence of the agent: baseline shifts reflect CAPS-induced inward clamp-current increment and reduction of the stepevoked inward current indicates depression. B: expanded sweeps illustrate better the initial facilitation (trace 19) followed by depression (traces 20-23). C Normalized peak current intensity changes. D: Means of normalized current intensities obtained in 10 cells under similar circumstances. Arrow marks onset of CAPS-induced changes, to where the data of individual cells were aligned before calculating mean values for every 6 $\mathrm{sec}$ intervals. Negative time refers to data before CAPS applied in different (150 $\mathrm{nM}$ to $1 \mu \mathrm{M})$

concentrations and for $20-60 \mathrm{sec}$ to individual cells 


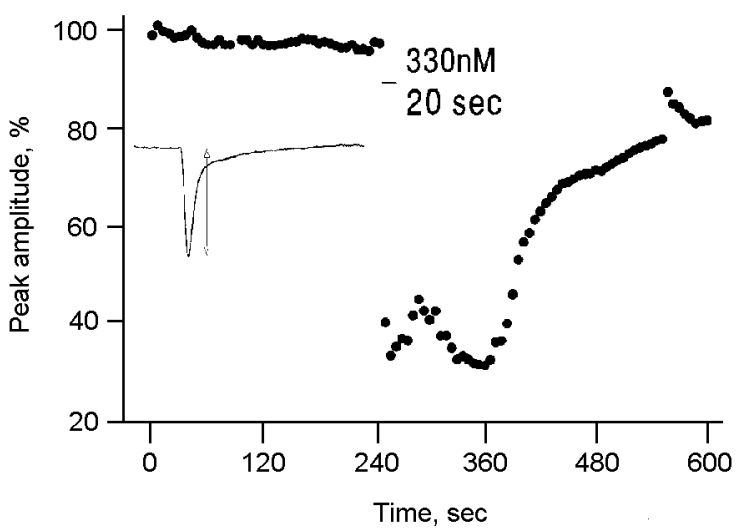

Fig. 3. CAPS-induced depression of V-gated fast inward current in a cell where no run down was detected. Insert shows initial part of a response to step pulse from -60 to $0 \mathrm{mV}$. No leak subtraction was used. Arrow indicates data measurement convention. The graph shows normalized data plotted against time, horizontal bar gives the period when CAPS was applied from close vicinity of the cell

Threshold of mixed currents and those which appeared to be pure TTXs variants were between -50 and $-45 \mathrm{mV}$, which was around $10 \mathrm{mV}$ more negative than the threshold of currents recorded in the presence of TTX. The TTX-r components also reached a peak at about $10 \mathrm{mV}$ more positive command potentials than the mixed or TTXs currents. Calculated half-maximum activation voltage in a sample of 5-5 cells was $-24 \pm$ 2.02 and $-16 \pm 1.28 \mathrm{mV}$ for TTXs and TTX-r currents, respectively.

Capsaicin $(330 \mathrm{nM}-1 \mu \mathrm{M})$ depressed the step evoked inward currents in many cells (Fig. 2). Sixteen cells were stimulated only by sets of three slightly different depolarizing steps (one of subthreshold and two of higher intensity) repeated every 6-8 sec before, during, and after CAPS application, all the others were also tested with ramp commands. Change of peak amplitude of step-evoked inward currents indicated effects of CAPS.

Depressed responses at the peak effect of the agent were in most cases $20-80 \%$ of the pre-CAPS currents to identical voltage. In average it was down to $32.78 \pm 26.42 \%$ $(n=27)$ as calculated from the amplitudes of the last response to step command before and the one at the peak effect of CAPS. Partial depression developed in 20-30 sec. Recovery was slow and usually incomplete after as long as 5 min washout.

In 6 cells the depression of step evoked inward current by CAPS was fast without any previous signs of run down (Figs 3 and 4B). In control cells ( $n=12$ not tested with CAPS) slow run down continued with similar rate for 10-15 min. Sudden acceleration of the decrease rate of step evoked current in close time relation with CAPS application was therefore evaluated also as depression in 22 cells. 
Responses to ramp commands in the presence of CAPS

CAPS (330 nM) increased the steepness of current response to depolarizing ramp commands. Effect of CAPS was monitored in 34 cells either with identical ramps delivered 6-8 sec apart or with a more complex protocol (Fig. 4A $\mathrm{A}_{1}$ ).

Increase of steepness of the current trace was rapid and transient, followed by a much slower decay with often complete recovery after about $3 \mathrm{~min}$ washout. In the representative example shown in Fig. 4, the slope of $\mathrm{I}-\mathrm{V}$ functions in the far negative range of membrane potential increased suddenly to a maximum (compare the superimposed lines 2 and 3 to line 4 in Fig. 4D), then it decreased gradually and became identical with the control by the time when line 7 was obtained. Like in many other cells, depression of the V-gated currents by CAPS coincided with the period of increase of the ramp I-V functions slope in the subthreshold range (Fig. 4. C and D).

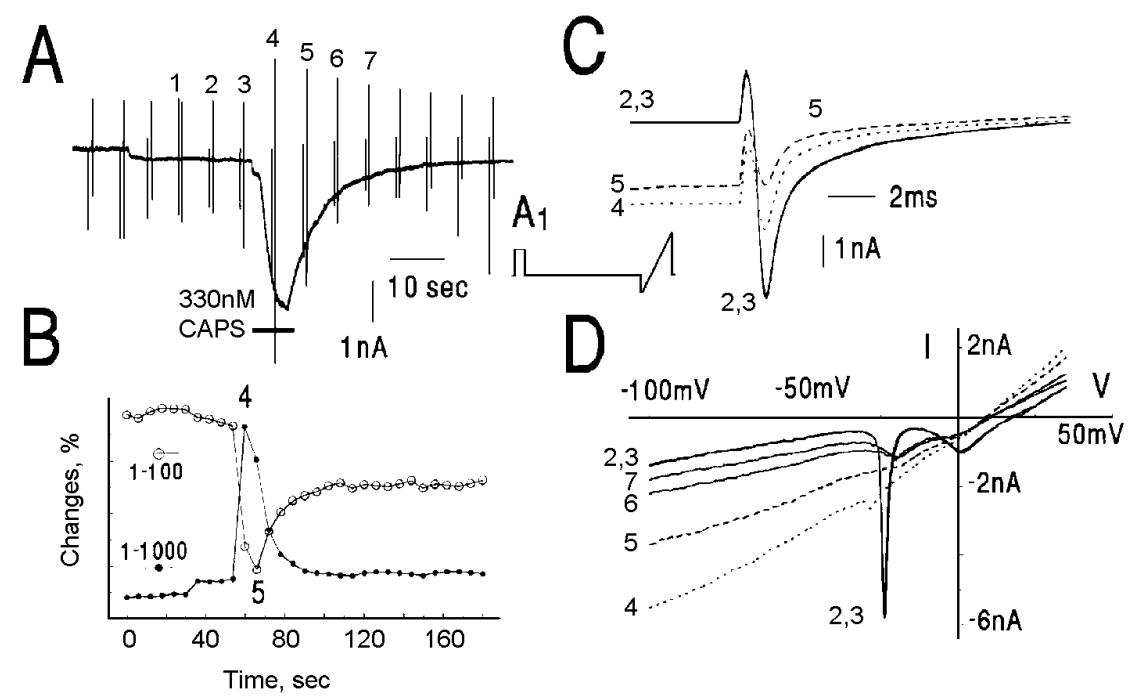

Fig. 4. CAPS modifies the I-V relationship of the membrane. All data from a single cell, held at $-60 \mathrm{mV}$. A: part of continuous recordings of the clamp-current, pairs of vertical lines mark timing of the repeated stepramp commands. Labels 1-7 help to identify records in A-D, horizontal bar marks application of $330 \mathrm{nM}$ CAPS. Insert $\mathrm{A}_{1}$ : Command protocol, a short depolarizing step to $0 \mathrm{mV}$ followed about $600 \mathrm{~ms}$ later by a ramp. B: Superimposed plots of normalized clamp-current increase (dots) and step command evoked current intensity decrease (circles). Clamp-current data came from the $20 \mathrm{~ms}$ periods just before the onset of step commands. The vertical scale is 10-times larger for the clamp-current data. Note that the clamp-current peaks before maximum depression of the step evoked current. C: Four superimposed responses to steps to $-10 \mathrm{mV}$, no leak subtraction. D: Superimposed I-V curves from ramp-command evoked data. Note the transient block of the fast inward current surge, the rapid increase (curves 3 to 4) followed by gradual decrease (curves 4-7) of the slope 
Recovery of the V-gated currents from depression lasted usually longer than the time needed for the changes of steepness to disappear. Current responses to more positive parts of the ramp commands were non-linear as illustrated in Figs 4, 5 and 6 in the present study. CAPS-induced changes of the part of $\mathrm{I}-\mathrm{V}$ curves derived from those current data were not quantified in the present work.

Slope of current responses to ramp commands in the portion between -95 and $-65 \mathrm{mV}$ were measured in pairs of two traces taken from each exposures of these 34 neurones. The slope was linear within that voltage range in the majority of neurones, or deviated slightly suggesting some rectification in others (e.g. Fig. 4D). That rectification was ignored. One of the traces was the last control available before any effect of CAPS was detected and the other yielded the steepest slope seen due to the agonist. That trace was often the same or just adjacent to the one in which the maximum depression of the step evoked inward current occurred, but did not always represented the time of peak inward clamp-current produced by CAPS (see below). The slope increased from 18.014 $\pm 8.79 \mathrm{pA} / \mathrm{mV}$ to $28.376 \pm 14.24 \mathrm{pA} / \mathrm{mV}(\mathrm{n}=34)$, an increment of $170.5 \pm 68 \%$ when the maximum and the pre-CAPS control were considered in each data pair. The calculated results include 4 cells when the slope changed less then $10 \%$ and 4 other cells in which the slope decreased by $14-27 \%$.

In a subset of 14 cells another pairs of traces were examined. One was again the control in which the main slope was $13.5 \pm 9.9 \mathrm{pA} / \mathrm{mV}$. This increased to $18.8 \pm$ $11.8 \mathrm{pA} / \mathrm{mV}$ at the time when the maximum depression of step-evoked inward currents were detected. At the moment of this $160 \%$ increment of slope, the step command evoked responses barely reached $25 \%$ of the size of peak current evoked before CAPS application. Within that group of 14 pairs of traces, the data suggested slope conductance increase in 7 neurones ( $233 \%$ increment from $11.24 \pm 4.68 \mathrm{pA} / \mathrm{mV}$ to $21.8 \pm$ $10.8 \mathrm{pA} / \mathrm{mV}$ ) but in the other 7 cells either some decrease or no change of the slope was observed (mean $87 \%$ of control, from $15.8 \pm 12.8 \mathrm{pA} / \mathrm{mV}$ to $14.4 \pm 11.7 \mathrm{pA} / \mathrm{mV}$ ).

\section{Effect of CAPS upon separate components of mixed current}

Experiments with TTX ( 22 cells) provided firm evidence that some of the cells generated fairly pure TTXs inward currents to depolarizing commands, while the mixed inward currents evoked in many others contained TTX-r components, too. Although the TTXs and TTX-r currents were both sensitive to CAPS, there were notable differences like for example transient facilitation of the TTXs component while rather pure depression of the TTX-r ones. This suggested unequal sensitivity of the components to CAPS. Further work is needed, but the data obtained so far excludes the possibility that CAPS would depress only a particular component of the mixed current evoked by depolarization. 


\section{Inward currents induced by CAPS}

In the majority of sensitive cells, which responded to CAPS by conductance increment, the agent increased the clamp current over $50 \mathrm{pA}$ in the inward direction at $-60 \mathrm{mV}$ membrane potential. Time course of small currents were simple: slow increase with about $15 \mathrm{sec}$ delay, rounded peak or prolonged maximum for 10-20 sec followed by gradual decay of a minute or so, while the CAPS was still present in the chamber. This type of current was typical in experiments when the CAPS was mixed into the bath. Direct application of CAPS to the cells produced larger responses with shorter delay and faster rising phase. The waveforms varied considerably: some had a quite short and single peak while others contained prolonged or sometimes multiple peaks. The decays were either slow or fast. Rapid, strong, or complex currents could be elicited by direct CAPS application only in cells cultured with NGF.

\section{Responses to high extracellular potassium ion concentration}

Application of $30-60 \mathrm{mM}$ high $\left[\mathrm{K}^{+}\right]_{\mathrm{e}}$ in the bath elicited simple clamp-current changes attributed to change of ionic gradients without activating the vanilloid receptors. Since the test fluid contained less sodium ions, the cells responded with reduced inward currents to depolarizing commands. The recovery was rapid and complete.

In 14 cells the slope of ramp-evoked membrane currents changed slightly or remained unaltered in the -95 to $-65 \mathrm{mV}$ command range under the effect of $50 \mathrm{mM}$ $\left[\mathrm{K}^{+}\right]_{\mathrm{e}}$. The same cells, when exposed to CAPS responded with currents of remarkably steeper slope indicating membrane conductance increase. In a subgroup of 7 cells the slope conductance increased to $110( \pm 12.7) \%$ at the peak depression of step evoked current by $50 \mathrm{mM}\left[\mathrm{K}^{+}\right]_{\mathrm{e}}$ in contrast with an increment to $233( \pm 40) \%$ at the peak depression by CAPS $(330 \mathrm{nM})$.

\section{Responses to repeated stimulations}

Fifteen cells responded two to four times to repeated application of CAPS with about 10 minutes long recovery periods between successive exposures. While repeated tests often induced weaker if any clamp-current increments, the depression of V-gated currents and increase of conductance could be observed consistently. The slope of the ramp evoked current in the -95 to $-65 \mathrm{mV}$ command range was $15.36 \pm 9.66 \mathrm{pA} / \mathrm{mV}$ before CAPS application and increased to a mean maximum of $20.64 \pm 13.15 \mathrm{pA} / \mathrm{mV}$ (an increment to $155 \pm 71 \%$ ) during the peak effect of $330 \mathrm{nM}$ CAPS. 


\section{B) Experiments with isolated cells not treated with NGF}

Both sensory neurones studied within 2-8 hours after isolation from enzymetreated TRG tissue (18 cells), and cultured cells fed by fluids without NGF $(n=36)$ responded only exceptionally (4 out of 28 tested) to CAPS application (concentrations $150 \mathrm{nM}$ to $3.3 \mu \mathrm{M}$ ). In the 4 responsive cells, the maximum of CAPS-induced clamp current remained below $-200 \mathrm{pA}$. Moderate depression or complete and permanent blockage of V-gated fast inward currents were observed.

\section{C) Experiments with slice preparations}

Cells were selected in TRG slices under visual control not deeper than about $50 \mu \mathrm{m}$ from the cut surface. Satellite cells were cleared away with positive pressure. Whole-cell tight-seal recordings were made from small $(21 \pm 5.2 \mu \mathrm{m}$ mean diameter) neurones. Altogether 67 TRG neurones were exposed to CAPS within a concentration range of $150 \mathrm{nM}$ to $3.3 \mu \mathrm{M}$ under slightly different conditions.

Cells were classified as sensitive to CAPS if they responded either with inward clamp-current exceeding $-100 \mathrm{pA}$ to the agent in nanomolar concentration (12 cells), or with some conductance change (14 cells). CAPS evoked inward clamp-current appeared to be weaker and slower in slice preparations than in cultured and NGF treated cells. CAPS in $3.3 \mu \mathrm{M}$ concentration failed to change the clamp-current in other 21 cells.

\section{Responses to step commands in the presence of CAPS}

Ten cells were selected for analysis from a group tested by a single depolarizing command repeated with 2-3 sec intervals. Current responses to subthreshold pulses increased to $674 \pm 420 \%(n=10)$ of the control in association with CAPS-induced inward clamp-currents. When the pulses were strong enough to activate fast inward currents, change of these currents during and after CAPS application was similar to that described for cultured cells above, depression of the $\mathrm{V}$-gated component being the dominant effect. In some experiments conductance changes were tested with series of increasing step commands during the periods before and after CAPS (150-330 nM) application and the effect was evaluated with comparing the two I-V plots generated from the data. Some changes of the I-V curves were noted but the time resolution of this approach was felt inadequate. 


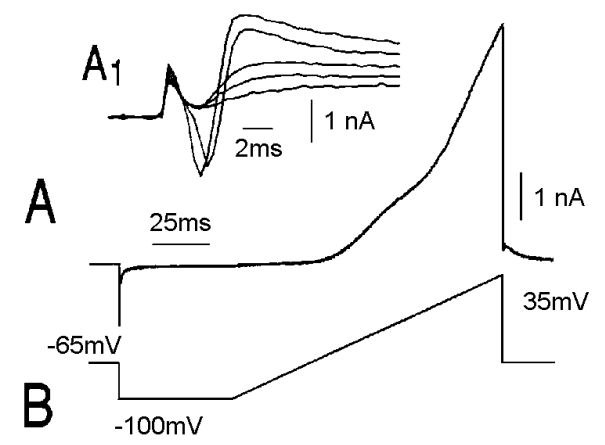

Fig. 5. Responses to CAPS application onto a cell in slice preparation. A: Current response to ramp-depolarization (B) with $0.8 \mathrm{mV} / \mathrm{ms}$ rate from $-100 \mathrm{mV}$ to $+35 \mathrm{mV}$. Insert $\mathrm{A}_{1}$ : Responses to step commands taken immediately after the ramp-test. Note the fast inward current to steps from $-85 \mathrm{mV}$ to -20 and $-15 \mathrm{mV}$. C: Two I-V curves taken after adjusting the ramp to reach $+80 \mathrm{mV}$ : CONTROL curve before, CAPS at the peak effect of $150 \mathrm{nM}$ CAPS. A dashed line is fitted by eyes to the middle portion of the CAPS curve. D: Time course of clamp-current changes, data displayed in the 0-200 Hz bandwidth. Vertical lines mark responses to ramp commands, their size only approximates the end points of original data. Numbers help trace identification in C-E. E: Conductance change calculated from the steady-state current in a step before each ramp. Insert $E_{1}$ : three superimposed responses to the initial part of the command, arrows mark data points considered for conductance calcula-tion, vertical differences among traces reflect CAPS induced inward clamp-current 

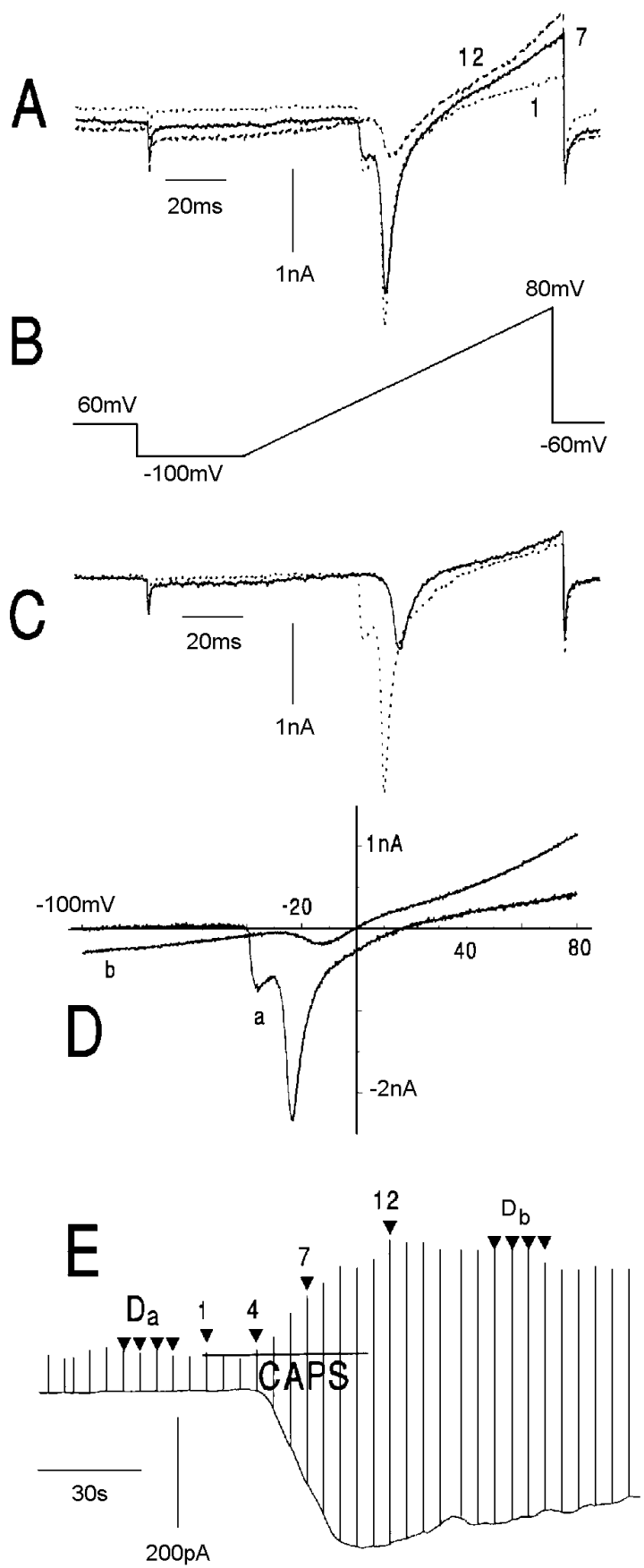

Fig. 6. Changes to responses to ramp commands in another slice preparation from a 3 days old rat. A: Current responses to ramp depolarization of $1.8 \mathrm{mV} / \mathrm{ms}$ rate. Three superimposed traces taken in the presence of $150 \mathrm{nM}$ CAPS, baseline differences indicate inward clamp-current, numbers help to identify data in E. B: Data of the command. C: Two current traces, the dotted one is the last control made before CAPS, the other indicates partial recovery about $10 \mathrm{~min}$ after CAPS. D: Two I-V curves generated from ramp-evoked currents: a) average of 4 responses taken during initial washin, and b) average of four others taken after washing out of CAPS. E: Time course of clampcurrent changes, data displayed in the 0-200 Hz bandwidth. Vertical lines mark times of responses to ramp commands, their size only approximates the end points of original data. Labels help data identification 
Changes of responses to ramp-commands in the presence of $150 \mathrm{nM} C A P S$

The linear part of the $\mathrm{I}-\mathrm{V}$ functions in the range negative to $-50 \mathrm{mV}$ changed markedly in a major fraction of cells tested with frequently repeated ramp commands before and in the presence of CAPS. In 18 CAPS sensitive cells, the mean of maximum steepness of the ramp-current data was $218 \pm 86 \%$ of the values obtained before the exposure. In CAPS insensitive cells, the slopes obtained before and after CAPS remained similar $(109 \pm 7.5, \mathrm{n}=11$, sensitivity limit $<130 \%)$.

Beside the change in the slope of ramp I-V curves, transient changes of rectification were also observed. For example inward rectification occurred for a while in cells which showed no rectification before. There was usually a period of CAPS induced effect when the membrane conductance was both high and linear over a wide voltage range. Reversal (zero-current) potentials of the I-V curves shifted along the voltage axis first to the positive direction then back to $0 \mathrm{mV}$.

Effect of CAPS upon ramp-evoked responses in the command range positive to $-50 \mathrm{mV}$ depended on the waveforms. The simplest changes were seen in cells dialised with cesium and tested with ramps which failed to activate rapid inward currents. In the presence of CAPS, slope of the I-V curves become steeper especially in the negative potential range. Gradual decrease of conductance back to the pre-CAPS level took about 10 minutes.

Nonlinear I-V curves obtained with ramp commands in cells studied with $\mathrm{KCl}$ filled pipette changed in a complex way in the presence of CAPS (Fig. 5). At the peak effect of the agent the slope of the negative limb of the curve increased while the opposite end of the curve remained almost the same. Each of the two I-V curves in Fig. $5 \mathrm{C}$ could be approximated with three regression lines. The calculated slope conductances for the three portions of the control curve were: $3 \mathrm{nS}$ in the range between -100 and $-70 \mathrm{mV}, 29.5 \mathrm{nS}$ between -30 and $0 \mathrm{mV}$, and $35.3 \mathrm{nS}$ for the portion positive to $+40 \mathrm{mV}$. The corresponding values for the curve taken at the peak effect of CAPS were $10.6 \mathrm{nS}, 31 \mathrm{nS}$, and $34.5 \mathrm{nS}$. Different numbers would represent the slopes of curves (not shown) obtained in the cell shortly before and after the peak of the inward current generated by CAPS (Fig. 5D), since the conductance changed rapidly as monitored by the simpler single step technique (Fig. 5E).

Ramps with higher rate of voltage increase (Fig. 6B) activated rapid inward currents which were inhibited by CAPS in the sensitive cells. This inhibition was accompanied by some enhancement of inward and outward currents at the negative and positive sides of the ramp command. Slightly different changes of the ramp I-V curves could be demonstrated with samples taken at different moments of the response (Fig. $6 \mathrm{E}$ ) but the changes persisted for several minutes during the wash-out period (Fig. 6D). 
Like in NGF treated cultured cells, CAPS application to cells in slice preparations depressed the fast inward current peak generated by the middle portion of the ramp command, but in slices the CAPS induced changes of the ramp-currents were more remarkable than the increment of clamp current.

\section{Discussion}

Main finding in the present paper is the CAPS-induced depression of V-activated currents of a subset of small sensory neurones. Data from cultured cells are compared with those obtained in slice preparations. Sensitive cells were the rarest (14\%) among the acutely isolated and the non-NGF treated cultured cells, near $40 \%$ of neurones was sensitive in slices, but approached $80 \%$ of the small diameter population in plates cultured for several days in the presence of NGF. This latter group contained the neurones in which the largest and fastest CAPS-induced clamp currents were observed in the present study. Depression of V-gated currents was observed in all cells where CAPS either induced inward current or merely increased the membrane slope conductance but did not occur in cells insensitive to CAPS. The depression certainly outlasted with minutes the presence of agonist in the vicinity of the membrane, but possible contribution of run down makes exploration of recovery difficult. We propose that depression of V-gated channels is a general consequence of vanilloid receptor activation. Critical role of NGF in the expression of VR-1 receptors is confirmed.

Extensive studies with intracellular and patch-clamp recordings from cultured DRG neurones have completed previous data on C-type neurones in DRG (16) and nodosal ganglia (25), and show that CAPS opens non-selective cation channels in a subpopulation of small sensory neurones $(1,2,5,6,8,11,19-23,28,29,48-50)$. In cultured cells the ionic mechanisms of the CAPS-induced depolarization, increase in membrane conductance, and their independence from the operation of V-gated channels have been determined and the proposal concerning the CAPS-induced cationic current (7) has been firmly established. On the other hand, the published data are less conclusive in regard to the diversity of the CAPS-induced currents, their rates of activation, and extents of desensitization. The discrepancies might be attributed to differences in culture medium or drug application techniques. Previous works $(3,8,14)$ considered importance of calcium entry involved in CAPS-induced inhibition of calcium channels.

Liu et al. (24) reported on current clamp experiments showing among other observations that CAPS $(1 \mu \mathrm{M})$ increases the threshold for the generation of action potentials only in CAPS-sensitive TRG neurones without signs of receptor desensitization. In V-clamp experiments they demonstrated that CAPS $(1 \mu \mathrm{M})$ inhibited 
the V-gated peak sodium current by $75 \%$ (with $0.45 \mu \mathrm{M} \mathrm{K} \mathrm{K}_{1 / 2}$ of the dose-dependent depression). The voltage dependence of the sodium current did not change, however the decay phase of the current became slower. Up to $-2 \mathrm{nA}$ level, the percent inhibition of total sodium current peak was proportional to the magnitude of the CAPS-induced inward current. In a subgroup of TRG cells studied in that respect they showed that TTX-r sodium currents were inhibited by CAPS and that the CAPS-induced depression of sodium currents could be blocked by the CAPS antagonist capsazepine.

In all preparations used here, V-activated inward currents were changed by nanomolar CAPS in the sensitive cells as follows: 1) Fast inward currents presumably due to opening of various $\mathrm{V}$-sensitive sodium and calcium channels $(8,9,15,17,35)$ activated in the range of -50 to $+10 \mathrm{mV}$ were invariably depressed by CAPS. This effect was observed both in cultured cells and in slice preparations. The amount of depression seemed to be unrelated with the magnitude of the CAPS induced inward clamp-current at $-60 \mathrm{mV}$ membrane potential. In cells where selective blocking agents were used, CAPS affected both the TTXs and TTX-r components, but their depression did not always run in parallel. The recovery of V-gated inward current was slow and often incomplete. Effect upon V-gated currents without the occurrence of marked inward current and the partial recovery observed in many cells indicated that the depression of V-gated currents could be separated from the toxic effects of high doses of CAPS $(3-5,18,43)$. 2) Outward currents evoked by voltages positive to $+10 \mathrm{mV}$, which presumably reflect activation of various potassium channels $(17,33)$ in cells not dialised with cesium ions, were also inhibited by CAPS. 3) Currents measured in the range of -100 to $-50 \mathrm{mV}$ of ramp commands yielded the expected linear I-V plots since hyperpolarization activated currents are weak or missing in small neurones (11). The membrane slope-conductance of the sensitive cells increased in the presence of CAPS. Reversal potential obtained either by extrapolation or measured directly with rampcommand techniques was changing rapidly in the initial period of CAPS effect, but usually stabilized at a level close to zero $\mathrm{mV}$ later. After washing out of the drug, slope conductance returned to the control value in some cells but remained higher in many others. CAPS-induced inward clamp-current and conductance changes can be explained by opening of the non-selective cation channels $(7,12)$.

The cellular mechanism of the reduction of V-gated inward currents by CAPS is not clear. In agreement with earlier studies on calcium currents $(5,14)$ it seems to be a secondary effect to activation of the VR-receptors $(12,44)$ since in cells where CAPS failed to increase the membrane conductance, no change of the V-gated currents were detected either. Since prolonged inhibition of V-gated calcium currents in cultured adult rat DRG neurones could not be reproduced when calcium was replaced by barium in the bath, inhibition of V-gated calcium channels was attributed to the influx of calcium through CAPS-activated cation channels $(5,14)$. Elevation of free calcium in the 
cytosol may affect other ion channels, too (17). Consequences of transient alteration of ionic gradients while the CAPS-sensitive cationic channels are open should also contribute to the effects reported here. For example changes of sodium and calcium gradient associated with VR1-activation must affect the V-gated inward currents due to alteration of driving forces. Possible errors in clamping of the membrane potential might allow transient changes of V-dependent properties including steady-state inactivation of the sodium channels, which in turn could be reflected by changes of the measured current intensity. However, consequences of clamping (uncompensated series resistance) errors are known to be more serious with strong (several nanoA) currents and likely quite small in the 50-200 pA range of inward CAPS-evoked current intensity in the majority of cells reported here. Details like apparently different sensitivity of TTXs and TTX-r sodium currents suggest that decrease of V-gated currents are not entirely due to CAPS induced $\mathrm{Na}^{+}$flux. Findings from the experiments with high $\left[\mathrm{K}^{+}\right]_{\mathrm{e}}$ also supported the assumption that activation of VR1 receptors by CAPS could modulate the V-gated channels in a way different from and possibly for longer time than that attributed simply to changes of ionic gradients.

In many earlier studies data on cultured cells from sensory ganglia $(1,2,5-8,11$, 20-30, 49, 50) a subset of small cells were characterized as CAPS-sensitive on the basis of inward current and enhancement of membrane conductance induced by CAPS. To our surprise, only a low percentage of small neurones were in TRG slices sensitive to CAPS. Many cells with diameter less than $30 \mu \mathrm{m}$ failed to respond either with conductance change or inward clamp-current to $3.3 \mu \mathrm{M}$ CAPS. Higher concentrations were not tested because it has been shown that at $10-100 \mu \mathrm{M}$ concentration range CAPS elicits a reversible reduction of V-gated outward current in all DRG cells and in many kinds of different neurones of non-mammalian or invertebrate species without any sign of CAPS-induced inward clamp-current $(3-5,18,43,44)$. These responses were considered to be unrelated to the presence and activation of capsaicin receptors $(4,12$, $18,43,44)$. Considerable diversity of CAPS-sensitive primary sensory neurones (40) on the one hand, and the large number and different cellular distribution of V-gated ionic currents on the other $(11,31,32,35,40)$ requires further efforts to determine details of interaction between channels sensitive to CAPS and to membrane potential in phenotypes of chemo-nociceptor cells.

Cultured cells are regularly exposed to NGF for days in concentration which has been shown to change the sensitivity to CAPS $(3,29,51)$. Furthermore tachyphylaxis to CAPS induced inward current can be inhibited by as short as $10 \mathrm{~min}$ exposure to $20 \mathrm{ng} / \mathrm{ml} \mathrm{NGF}$ (38), much lower concentration than usually used for incubation of cell cultures. The profound and fast effect of NGF on nociceptive neurones was indicated also by prolongation of the action potentials in sensory neurones within minutes (37) and promotion of in vivo development of nociceptor phenotype $(3,26)$. In slice 
preparations (34) somata of sensory neurones remain in their natural tissue environment and exogenous NGF-induced alterations of the CAPS-induced responses can be avoided. Depression of ramp-induced fast inward currents by CAPS offers a quick test of sensitivity of cells to that pungent agent. It remains to be determined whether weak CAPS-induced current found in slice preparations is due to technical reasons involved in making the slice preparation or to protective effects of glial cells. Alternatively weakness of currents could be explained in the frame of missing over-expression of VR1 receptors, or by assuming that the very strong and rapid CAPS-induced currents (20-23) can only be detected in particular phenotypes of sensory neurones. Strong and rapid current variants were observed in our experiments only in cultured neurones exposed to external NGF for several days.

The pronounced and lasting blockage of V-activated inward currents by CAPS in concentrations lower or close to the EC50 value for producing depolarization $(216 \mathrm{nM})$, or decrease in input resistance (264 nM) of rat DRG neurones (5), or activation of C-polymodal nociceptors in vitro $(350 \mathrm{nM})$ (36) has important functional relevance. Close arterial injection of CAPS elicits discharges in C-polymodal nociceptors in the rat and rabbit $(42,45)$. Single unit studies revealed that systemic treatment of rats $(45)$ with CAPS, or close arterial injection of large doses of CAPS in rabbits (42) desensitizes the C-polymodal nociceptors. This sensory desensitization is characterized by a decreased responsiveness of the nociceptors to natural stimuli like noxious heat, mechanical stimulation or bradykinin which is taken as evidence that transduction process of these receptors are impaired in addition to the desensitization of the capsaicin-gated ion channel. Furthermore the lack of simultaneous blockage of the three types of stimulation excluded the failure of impulse conduction in their axon $(42,45)$. CAPS induces tachyphylaxis or desensitization to capsaicin-type pungent agents also in cultured DRG or TRG neurones $(4,14,22)$. The capsaicin receptor VR1 $(12,48)$ is sensitive also to another vanilloid compound resiniferatoxin (39) and noxious heat stimuli. Hence longlasting pharmacological desensitization of VR1 would explain the sensory desensitization to noxious heat, but not to mechanical stimuli, or to bradykinin, because these latter two stimuli depolarize the nerve terminals by other membrane mechanism $(3,52)$. On the assumption that membrane effects of CAPS are identical at the soma and at the sensory terminals of the cell, functional desensitization of the C-polymodal nociceptors can be explained by inhibition of $\mathrm{V}$-activated currents at the regenerative region. Functional desensitization seems to be important in the analgesic effect of CAPS particularly at local application. Mechanisms of lasting refractory state following stimulation by vanilloids is far from being clear in spite of the obvious therapeutic potential. The process is a complex cascade (40) which appears to depend strongly on the membrane potential (30). Since CAPS caused a capsazepine-sensitive increase of cAMP and an analogue (CPT-cAMP, $1 \mathrm{mM}$ ) inhibited the total sodium current in TRG 
neurones, Liu et al. (24) attributed the effect at least in part to PKC- and PKA mediated modulations of sodium channels. This cAMP pathway would add to other secondmessengers such as calcium $(7,13,14,19,22)$ known to modulate $\mathrm{V}$-gated channels as well as VR1 receptors. Thus neuronal (polymodal nociceptor) sensitivity can be diminished by CAPS at least in two ways, one is receptor desensitization in itself the other is inhibiton of V-gated sodium currents.

To sum up, inward current evoked by capsaicin on small sensory neurones in slice preparation or on cells isolated acutely from the rat trigeminal ganglia are much less pronounced than that observed on cultured cells kept in NGF containing media. Nevertheless capsaicin from a concentration of $150 \mathrm{nM}$ inhibits sodium and calcium mediated currents for several minutes in cells in all three types of preparations where it elicits inward current and/or increases membrane conductance. Characteristics of the capsaicin-induced changes in V-gated responses are described in some detail under different conditions. The results suggest that depression of the V-gated currents can play an important role in the functional desensitization of the sensory receptors and in the analgesic effect induced by the agent.

\section{Acknowledgements}

We thank Dr. Norbert Hájos and Dr. Zoltán Rusznák for valuable advises, helps and participation in some experiments during the early period of this project. Financial support was obtained from grants of OMFB MU 022/97.07.14, FKFP 1164/1997, OTKA:T 016945, T-034911, A 234, ETT 03-382/2000 and NRDP 1/047/2001.

\section{REFERENCES}

1. Baccaglini PI, Hogan PG: Some rat sensory neurones in culture express characteristics of differentiated pain sensory cells. Proc. Natl. Acad. Sci. (USA) 80, 594-598 (1983)

2. Baumann KT, Burchiel KJ, Ingram SL, Martenson ME: Responses of adult human dorsal root ganglion neurones in culture to capsaicin and low pH. Pain 65, 31-38 (1996)

3. Bevan S (1996): Intracellular messengers and signal transduction in nociceptors. In Neurobiology of Nociceptors (eds. Belmonte C. and Cervero F.). Oxford Univ. Press, Oxford. pp. 298-324

4. Bevan S, James JF, Rang HP, Winter J (1987): The mechanism of action of capsaicin: A sensory neurotoxin. In Neurotoxins and their Pharmacological Implications (ed. Jenner P.). Raven Press, New York, pp. 261-277

5. Bevan S, Docherty RJ (1993): Cellular mechanisms of the action of capsaicin. In Capsaicin in the Study of Pain (ed. Wood JN.). Academic Press, London, pp. 27-44

6. Bevan S, Docherty RJ (1996): The ionic basis of capsaicin-evoked responses. In Neurogenic Inflammation (eds. Gepetti P. and Holzer P.). CRC Press, pp. 53-67

7. Bevan S, Szolcsányi J: Sensory neuron specific actions of capsaicin: mechanisms and applications. Trends Pharmac. Sci. 11, 330-333 (1990) 
8. Bleakman D, Brorson JR, Miller RJ: The effects of capsaicin on voltage-gated calcium currents and calcium signals in cultured dorsal root ganglion cells. Br. J. Pharmacol. 101, 423-431 (1990)

9. Caffrey JM, Eng DL, Black JA, Waxman SD, Kocsis JD: Three types of sodium channels in adult rat dorsal root ganglion neurones. Brain Res. 592, 283-297 (1992)

10. Carbone E, Lux HD, Carabelli V, Aicardi G, Zucker $\mathrm{H}: \mathrm{Ca}^{2+}$ and $\mathrm{Na}^{+}$permeability of high-threshold $\mathrm{Ca}^{2+}$ channels and their voltage-dependent block by $\mathrm{Mg}^{2+}$ ions in chick sensory neurones. J. Physiol. (London) 504, 1-15 (1997)

11. Cardenas CG, Del Mar LP, Scroggs RS: Variation in serotonergic inhibition of calcium channel currents in four types of rat sensory neurones differentiated by membrane properties. J. Neurophysiol. 74, 1870-1879 (1995)

12. Caterina MJ, Schumacher MA, Tominaga M, Rosen TA, Levine JD, Julius D: The capsaicin receptor: a heat-activated ion channels in the pain pathway. Nature 389, 816-824 (1997)

13. Cholewinski A, Burgess GM, Bevan S: The role of calcium in capsaicin-induced desensitization in rat cultured dorsal root ganglion neurones. Neuroscience 55, 1015-1023 (1993)

14. Docherty RJ, Robertson B, Bevan S: Capsaicin causes prolonged inhibition of voltage-activated calcium currents in adult rat dorsal root ganglion neurones in culture. Neuroscience 40, 513-521 (1991)

15. Elliott AA, Elliott JR: Characterization of TTX-sensitive and TTX-resistant sodium currents in small cells from adult rat dorsal root ganglia. J. Physiol. (Lond.) 463, 39-56 (1993)

16. Heyman I, Rang HP: Depolarizing responses to capsaicin in a subpopulation of rat dorsal root ganglion cells. Neuroscience Letters 56, 69-75 (1985)

17. Hille B: Ion Channels of Excitable Membranes. Sinauer, Sunderland, MA (1992)

18. Holzer P: Capsaicin: cellular targets, mechanisms of action, and selectivity for thin neurones. Pharmacol. Rev 43, 143-201 (1991)

19. Koplas PA, Rosenberg RL, Oxford GS: The role of calcium in the desensitization of capsaicin responses in rat dorsal root ganglion neurones. J. Neuroscience 17, 3525-3537 (1997)

20. Liu L, Simon SA: A rapid capsaicin-activated current in rat trigeminal ganglion neurones. Proc. Natl. Acad. Sci. (USA) 91, 738-741 (1994)

21. Liu L, Simon SA: Similarities and differences in the currents activated by capsaicin, piperine, and zingerone in rat trigeminal ganglion cells. J. Neurophysiol. 76, 1858-1869 (1996)

22. Liu L, Simon SA: Capsaicin-inducated currents with distinct desensitization and $\mathrm{Ca}^{2+}$ dependence in rat trigeminal ganglion cells. J. Neurophysiol. 75, 1503-1514 (1996)

23. Liu L, Wang Y, Simon SA: Capsaicin-activated currents in rat dorsal root ganglion cells. Pain 64, 191-195 (1996)

24. Liu L, Oortgiesen M, Li L, Simon SA: Capsaicin inhibits activation of voltage-gated sodium currents in capsaicin-sensitive trigeminal ganglion neurons. J. Neurophysiol. 85, 745-58 (2001)

25. Marsh SJ, Stansfeld CE, Brown DA, Davey R, McCarthy D: The mechanism of action of capsaicin on sensory C-type neurones and their axons in vitro. Neuroscience 23, 275-289 (1987)

26. Mendell LM (1996): Development of the nociceptor phenotype: role of nerve growth factor. In Neurobiology of Nociceptors (eds. Belmonte C. and Cervero F.). Oxford Univ. Press. Oxford, pp. 455-472

27. Nagy I, Rang H: Noxious heat activates all capsaicin-sensitive and also a sub-population of capsaicininsensitive dorsal root ganglion neurones. Neuroscience 88, 995-997 (1999)

28. Oh U, Hwang SW, Kim D: Capsaicin activates a nonselective cation channels in cultured neonatal rat dorsal root ganglion neurones. J. Neurosci. 16, 1659-1667 (1996)

29. Petersen M, La Motte RH: Relationships between capsaicin sensitivity of mammalian sensory neurones, cell size and type of voltage gated Ca-currents. Brain Res. 561, 20-26 (1991)

30. Piper AS, Yeats JC, Bevan S, Docherty RJ: A study of the voltage dependence of capsaicin-activated membrane currents in rat sensory neurones before and after acute desensitization. J. Physiol. (London) 518, 721-733 (1999) 
31. Rush AM, Brau ME, Elliott AA, Elliott JR: Electrophysiological properties of sodium current subtypes in small cells from adult rat dorsal root ganglia. J. Physiol. (London) 511, 771-789 (1998)

32. Rusin KI, Moises HC: $\mu$-Opioid receptor activation reduces multiple components of high-threshold calcium current in rat sensory neurones. J. Neurosci 15, 4315-4327 (1995)

33. Safronov BV, Vogel W: Properties and functions of Na-activated $\mathrm{K}$ channels in the soma of rat motoneurones. J. Physiol. 497, 3, 727-734 (1996)

34. Scholz A, Gru $\beta$ M, Vogel W: Properties and functions of calcium-activated $\mathrm{K}^{+}$channels in small neurones of rat dorsal root ganglion studied in a thin slice preparation. J. Physiol. (London) 513 , 55-69 (1998)

35. Scroggs RS, Fox AP: Calcium current variation between acutely isolated adult rat dorsal root ganglion neurones of different size. J. Physiol. (Lond) 445, 639-658 (1992)

36. Seno N, Dray A: Capsaicin-induced activation of fine afferent fibres from rat skin in vitro. Neuroscience 55, 563-569 (1993)

37. Shen KF, Crain SM: Nerve growth factor rapidly prolongs the action potential of mature sensory ganglion neurones in culture, and this effect requires activation of Gs-coupled excitatory kappaopioid receptors on these cells. J. Neurosci. 14, 5570-5579 (1994)

38. Shu X-Q, Mendell L: Neurotrophin effects on capsaicin-induced inward currents of sensory neurones in the rat. Abstr. Soc. Neurosci, No. 319.10 (1998)

39. Szállási A, Blumberg PM: Resiniferatoxin and its analogs provide novel insights into the pharmacology of the vanilloid (capsaicin) receptor. Life Sci. 47, 139-148 (1990)

40. Szállási A, Blumberg PM: Vanilloid (capsaicin) receptors and mechanisms. Pharmacological Rev. 51, 159-211 (1999)

41. Szolcsányi J: A pharmacological approach to elucidation of the role of different nerve fibres and receptor endings in mediation of pain. J. Physiol. (Paris) 73, 251-259 (1977)

42. Szolcsányi J: Selective responsiveness of polymodal nociceptors of the rabbit ear to capsaicin, bradykinin, and ultraviolet irradiation. J. Physiol. 338, 9-23 (1987)

43. Szolcsányi J (1990): Capsaicin, irradiation and desensitization: neurophysiological basis and future perspectives. In Chemical Senses, Vol. 2: Irradiation (eds. Green B. G., Mason J. R. and Kare M. R.). Marcel Dekker, Inc. New York, pp. 141-169

44. Szolcsányi J (1993): Actions of capsaicin on sensory receptors. In: Capsaicin in the Study of Pain (ed. Wood JN.). Academic Press, London, pp. 1-26

45. Szolcsányi J, Anton F, Reeh PW, Handwerker HO: Selective excitation by capsaicin of mechano-heat sensitive nociceptors in rat skin. Brain Res. 446, 262-268 (1988)

46. Szolcsányi J, Jancsó-Gábor A: Sensory effects of capsaicin congeners I. Relationship between chemical structure and pain producing potency of pungent agents. Arzneim.-Forsch. (Drug Res.) 25, 1877-1881 (1975)

47. Szőke É, Balla Zs, Csernoch L, Czéh G, Szolcsányi J: Interacting effects of capsaicin and anandamide on intracellular calcium in sensory neurones. Neuroreport 11, 1949-52 (2000)

48. Tominaga M, Caterina MJ, Malmberg AB, Rosen TA, Gilbert H, Skinner K, Baumann BE, Basbaum AI, Julius D: The cloned capsaicin receptor integrates multiple pain-producing stimuli. Neuron 21 , 531-543 (1998)

49. Vlachová V, Vyklicky L: Capsaicin-induced membrane currents in cultured sensory neurones of the rat. Physiol. Res. 42, 301-311 (1993)

50. Vyklicky L, Knotkova-Urbancova H, Vitaskova Z, Vlachova V, Kress M, Reeh PW: Inflammatory mediators at acidic $\mathrm{pH}$ activate capsaicin receptors in cultured sensory neurones from newborn rats. J. Neurophysiol. 79, 670-676 (1998)

51. Winter J, Forbes CA, Sternberg J, Lindsay RM: Nerve growth factor (NGF) regulates adult rat cultured dorsal root ganglion neuron responses to the excitotoxin capsaicin. Neuron 1, 973-981 (1988)

52. Wood JN, Docherty R: Chemical activators of sensory neurones. Annu. Rev. Physiol. 59, 457-482 (1997) 